\title{
Estimating Solar PV Potential for Sustainable Energy Planning in Tier-II Cities of India: Case of Bhopal City
}

\author{
Kakoli Saha*, Nikhil R. Mandal \\ Department of Planning, School of Planning and Architecture, Bhopal, India \\ Email: *kakolisaha@spabhopal.ac.in
}

How to cite this paper: Saha, K., \& Mandal, N. R. (2016). Estimating Solar PV Potential for Sustainable Energy Planning in Tier-II Cities of India: Case of Bhopal City. Current Urban Studies, 4, 356-375.

http://dx.doi.org/10.4236/cus.2016.43024

Received: July 19, 2016

Accepted: September 27, 2016

Published: September 30, 2016

Copyright $\odot 2016$ by authors and Scientific Research Publishing Inc. This work is licensed under the Creative Commons Attribution International License (CC BY 4.0).

http://creativecommons.org/licenses/by/4.0/ (c) (1) Open Access

\begin{abstract}
With growing economy, several cities and towns in India are experiencing a substantial growth in their gross and peak electricity demands. While Municipal Corporations and the electricity supply agencies are struggling to cope with growing energy demand of cities, many think solar electricity generation through rooftop Photovoltaic (PV) is a viable solution for this problem. Quantification of available rooftop is necessary to estimate the potential of energy generation in Indian cities through rooftop solar PV panels. This paper proposes an automated object-oriented approach to extract total available area of residential rooftops. A smaller residential neighbourhood in Bhopal city has been selected as Test Site to test the proposed method. Data sets used are World View 2 Stereo pair and Multispectral images. It is found that the test area has the potential to meet $265 \%$ of its daily local energy demand through rooftop solar PV panels. Though Indian government had announced separate scheme under the Jawaharlal Nehru National Solar Mission (JNNSM) to promote installation of rooftop PV, development of this sector is still in nascent stages. This paper also suggests some policy level interventions to promote rooftop PV at domestic level in similar tier-II cities of India.
\end{abstract}

\section{Keywords}

Digital Surface Model, Object-Oriented Classification, Rooftop PV, Solar Potential, Electricity Demand

\section{Introduction}

At the 2009 climate summit, India undertook to cut its greenhouse gas (GHG) emissions intensity by $20 \%-25 \%$ by 2020 compared with 2005 levels. As the Indian econo- 
my registered GDP growth of 7.5\% (2013-2014), its greenhouse gas (GHG) emissions have risen correspondingly. Given that more than half of anthropogenic GHG emissions comprise carbon dioxide from fossil fuel combustion, the mitigation of climate change predominantly concerns our energy use (Wiginton et al., 2010). Energy use reform is necessary which requires expansion of electricity generation from renewable sources of energy including wind, solar, biomass and small hydropower. In particular, the direct conversion of sunlight into electricity by solar photovoltaic (PV) technology possesses great untapped potential and represents a technically viable and sustainable solution to energy demands (Neuhoff, 2005; Pearce, 2002).

The National Action Plan for Climate Change (NAPCC) released in June 2008 outlines a national strategy that aims to enable the country to adopt climate change mitigation actions and enhance the ecological sustainability of India's development path. The Jawaharlal Nehru National Solar Mission (JNNSM) is one of the eight missions of India's National Action Plan on Climate Change (NAPCC) that elucidates the nation's vision for solar technology: installation of $22 \mathrm{GW}$ of solar capacity by 2022 . The Mission has adopted a 3-phased approach, spanning the remaining period of the 11th Plan and first year of the 12th Plan (up to 2012-13) as Phase 1, the remaining 4 years of the 12th Plan (2013-17) as Phase 2 and the 13th Plan (2017-22) as Phase 3. Under Phase I of JNNSM, a separate scheme called "Rooftop PV and Small Scale Solar Generation Program (RPSSGP)" was implemented.

According to Ministry of New and Renewable Energy [MNRE], India has the potential of generating $124 \mathrm{GW}$ of electricity from Rooftop PV installation. The estimation was done on the basis of census data available on percentage of concrete roof and population. The problem with this kind of estimation is three-fold: 1) census data is available in every ten years; whereas, land-use pattern of Indian cities is very dynamic. For successful implementation of JNNSM, up-to-date data is required in every three to four years; 2) In India, census data for dwelling units is available for wards [administrative divisions within cities] which are different from electricity distribution zones. As a result, estimated solar potential from census data cannot be compared with the electricity demand of that area.

To overcome these challenges one needs a quicker and repeatable technique which can provide us rooftop data at any spatial scale. This paper proposes an automated method to extract residential rooftop area at neighbourhood level.

\section{Literature Review}

Several authors have applied GIS techniques to extract rooftop surface area for assessing solar PV potential. Following are some examples as Table 1.

Unfortunately, methods followed in these past research works are not directly applicable for determining the rooftop PV potential of the test area of Bhopal city for following reasons: 1) high resolution orthophotoes are not available for Bhopal 2) there is no cadastre plug-in for Google Earth TM available in India 3) on-screen digitization on Google Earth is extremely time consuming and subjective. To address these chal- 
Table 1. Review of research work applying GIS techniques to extract rooftop surface area.

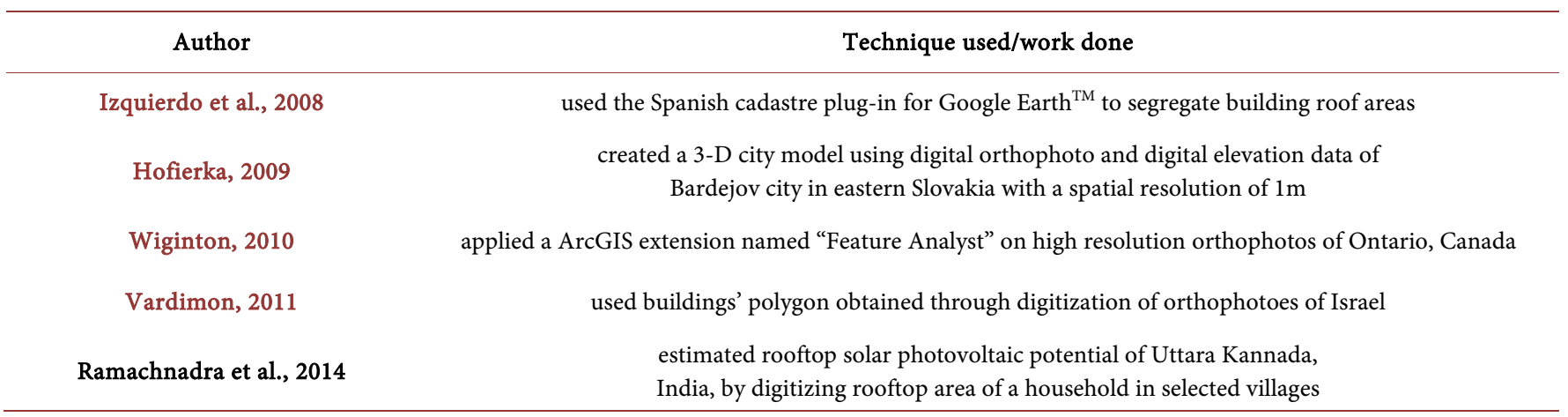

lenges, this paper proposes an object-oriented approach for automated extraction of residential roof area in Indian cities.

Object-based image analysis is based on recognition of individual objects rather than pixel-by pixel classification. Such an approach greatly reduces the number of units and eliminates the "salt-and-pepper" effect common in per-pixel classifiers (eCognition Developer, 2014). Also, when urban features are extracted as individual polygons, information such as asymmetry, size, and orientation can be obtained automatically for each polygon, whereas those details are inaccessible in pixel by-pixel classifications (Saha et al., 2011).

Object based method has long been used to extract urban features from space borne remote sensing imagery (Herold et al., 2002, Giada et al, 2003, Shackelford and Davis 2003, Marangoz et al. 2004). Urban rooftops in particular, have been extracted by Aldred et al. (2011) using object based classification through eCognition Developer. None of the work in object-oriented classification, to date, however, has attempted roof area quantification for PV deployment.

Quantification of rooftop area will not only help to estimate rooftop PV potential of any city, but also with regards to other applied urban sustainability initiatives such as solar thermal/water heating, green roofs and water harvesting. This is particularly important for Bhopal city which is one of the 60 cities/towns that are proposed to be developed as Solar/Green Cities under a scheme for "Development of Solar Cities" launched by MNRE.

In this study, an automated extraction method was proposed for quantification of the roof area. The method was developed in Object-Oriented environment available through eCognition Developer software. Satellite images of the test area were acquired and preprocessed to derive layers of relief shaded image and Normalized Digital Surface Model or nDSM. The derived layers were then merged with multispectral image and object-oriented classification was performed on the merged image. Classified building roof-tops were then extracted as individual polygons. Once the polygons were extracted, total roof area was also calculated by the software. The area was further used to estimate the solar energy potential of the test site through rooftop PV. The above mentioned method is described in detail in Methodology section below (Section 6). 


\section{Rooftop PV Programmes in India}

Rooftop PV (RTPV) systems are PV systems installed on rooftops of residential, commercial or industrial premises. The electricity generated from such systems could either be entirely fed into the grid or used for self consumption. Rooftop PV provides benefits at different level described in the flow chart below (Figure 1).

In spite of the benefits mentioned above, overall use of rooftop solar PV is in relatively nascent stages in India. To popularize PV, GOI [Government of India] has adopted many means, framed policies and launched several schemes. Some of these are briefly explained in Table 2 .

Table 2. Schemes/incentives/means for promoting rooftop solar PV programs3. Data acquesition.

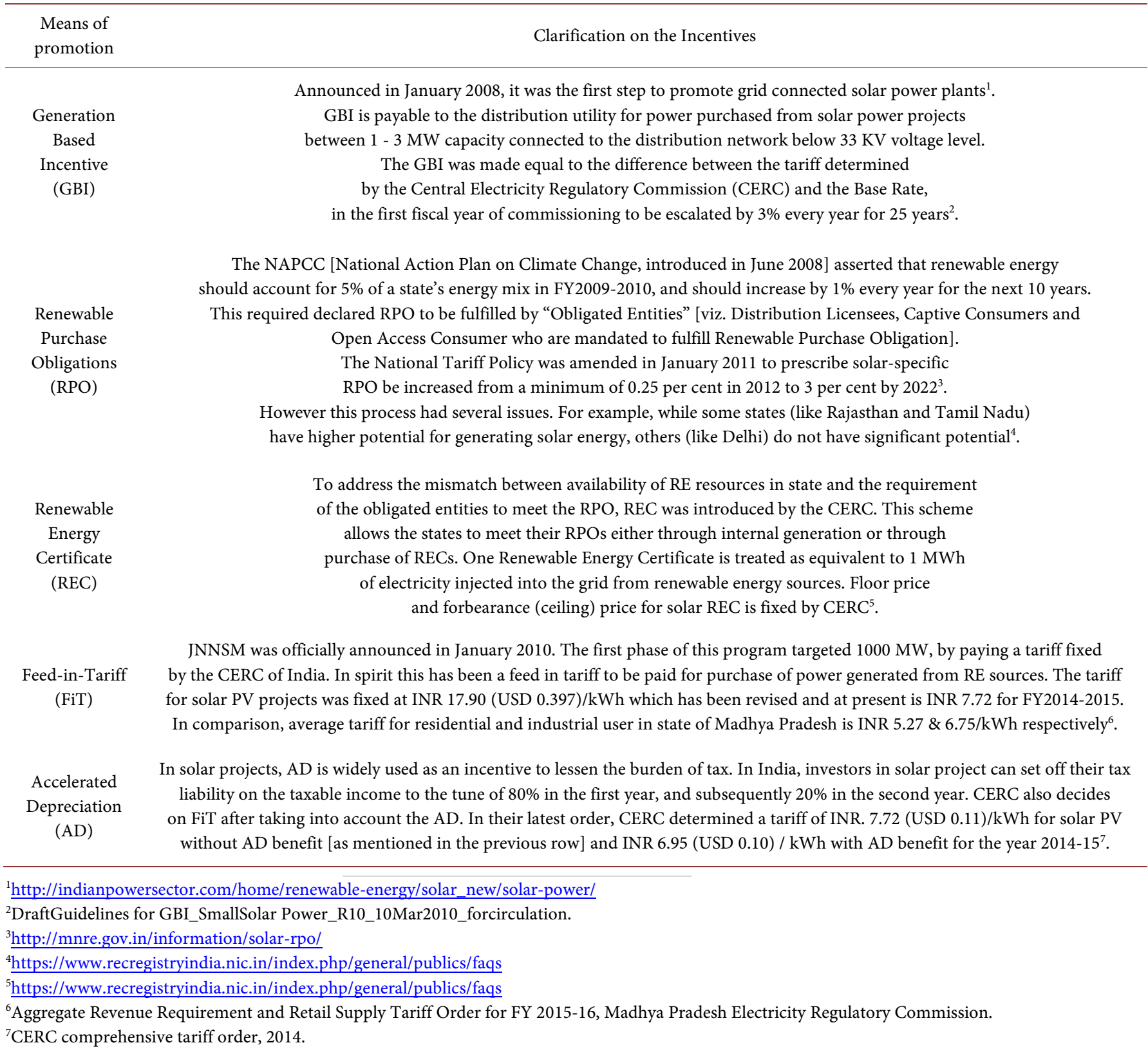




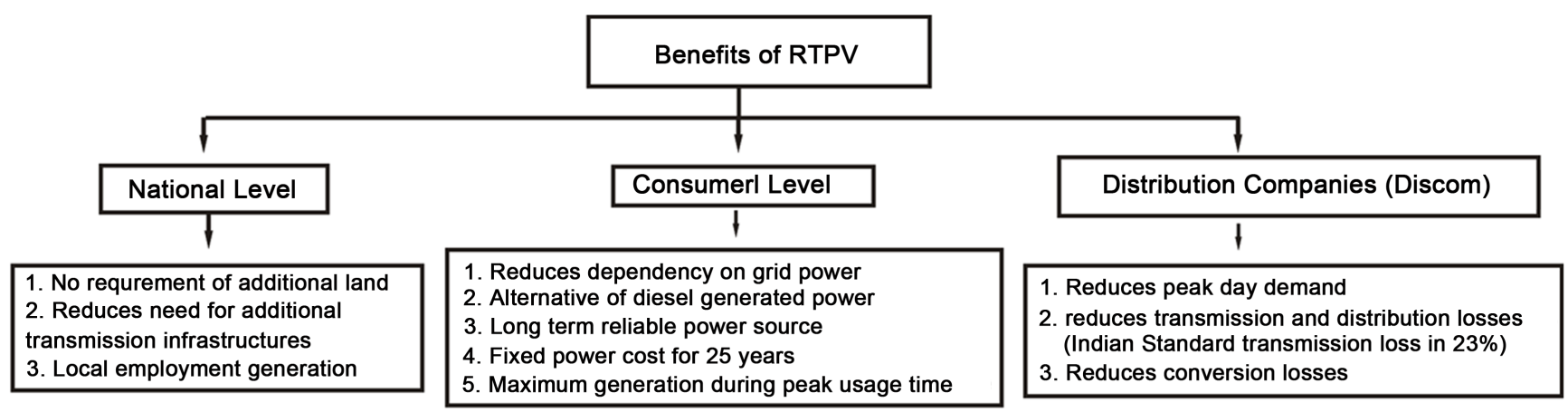

Figure 1. Flow chart showing benefits of rooftop solar PV at different level.

MNRE also has a pilot scheme to provide capital subsidy of $30 \%$ on the cost of solar PV system. A maintenance charge for 2 years is allowed to be included in the system cost. Under this scheme, project sizes may vary between $100 \mathrm{~kW}$ to $500 \mathrm{~kW}$. MNRE also encourages residential customers to avail bank loans to install Rooftop PV. Nine Banks including Bank of India, Syndicate Bank, State Bank of India etc have been given instructions to extend loan for Grid Interactive Rooftop Solar PV Plants as home loan/ home improvement loan. MNRE plans to start "net metering" systems in India soon to promote rooftop PV. A net-metering mechanism allows for a two-way flow of electricity wherein the consumer is billed only for the "net" electricity (total consumptionown PV production) supplied by DISCOMs. Karnataka, West Bengal already has "net-metering" policy and Rajasthan is planning to launch the same. Besides, to effectively implement JNNSM, several states have formulated their own relevant policies and regulations together with additional incentive schemes to promote rooftop PV installation. In spite of all of above, currently Rooftop PV contributes only $6 \%$ of total installed grid connected solar PV capacity.

\section{Madhya Pradesh Solar Policy 2012}

The Government of Madhya Pradesh (GoMP) acknowledges the increasing concern related to climate change, global warming and has recognized the urgent need to address these issues. The state of Madhya Pradesh is endowed with high solar radiation with around 300 days of clear sun. The state offers good sites having potential of more than $5.5 \mathrm{kWh} / \mathrm{sqm} /$ per day for installation of Solar based power projects (MNRE). To attract solar based projects, GoMP has specifically launched revised Investor/Developer friendly policy on 2012. The objective of the policy was to build a favourable atmosphere for Private Sector to set up Solar Power based projects in the State. The highlights of the policy are:

1) All Solar power projects (including captive units) will be eligible for exemption from payment of electricity duty and cess for a period of 10 years from the date of commissioning of the project.

2) GoMP will provide a grant of four percent (4\%) on wheeling charges.

3) Banking of $100 \%$ of energy in every financial year shall be permitted. 
4) The Industrial Consumers opting to buy power from Solar Power Project set up for captive use or under REC mode shall be allowed corresponding pro-rata reduction in Contract Demand on a permanent basis.

5) Third Party sale within or outside the State of M.P. will be allowed.

6) The Solar projects implemented under this Solar Policy will have the status of industry and will be eligible for all benefits under Industrial Promotion Policy.

7) The equipments purchased for installation of Solar power plants under the policy shall be exempted from Value Added Tax and Entry Tax.

8) Clean Development Mechanism (CDM) benefits will be provided to the solar power project Developers/Investors.

9) The RPO target was increased from $0.60 \%$ (FY 2012-13) to 1.00\% (FY 2014-15).

Unfortunately the above policies had little effect on rooftop solar PV installation in MP. MP has the lowest installed rooftop solar PV capacity compared to other states (Figure 2(a)) in spite of having more Global Horizontal Irradiance (GHI) than Indian average (Figure 2(b)).

Above discussion points to an imperative that MP needs separate rooftop solar policy like other states. Quantification of potential rooftop availability for PV deployment will help to formulate the rooftop PV policy of MP. This paper proposes an automated method to extract residential roof area which will ultimately help to estimate the solar PV output potential of the given area.

\section{Study Area and Data Description}

The study area is a residential sector within the administrative boundaries of Bhopal Municipal Corporation (BMC), Bhopal city, Madhya Pradesh, India (Figure 3(a)).

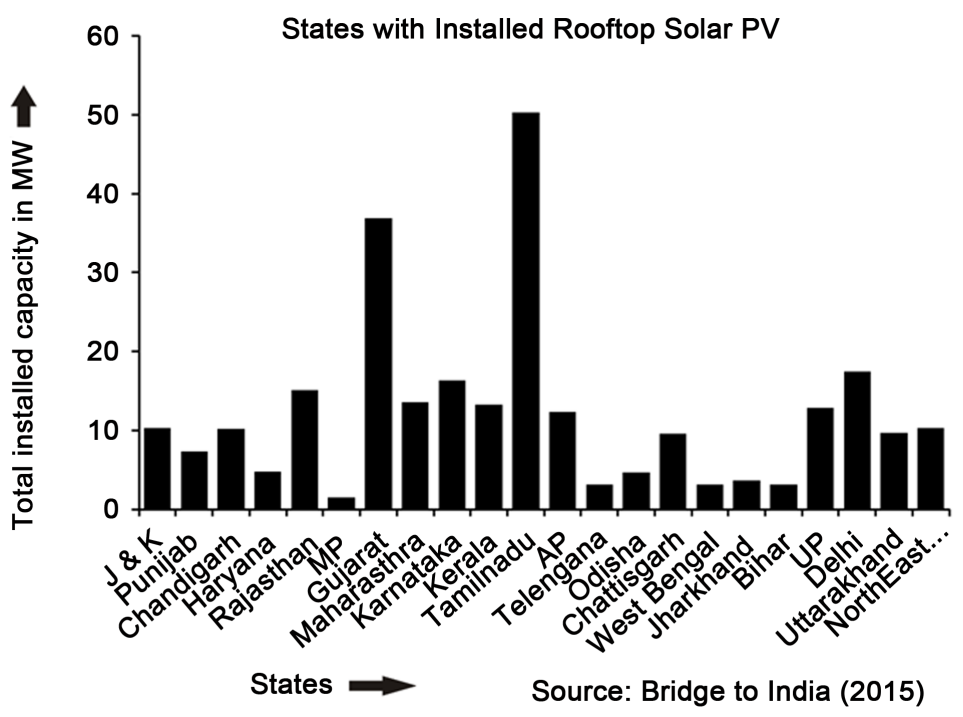

(a)

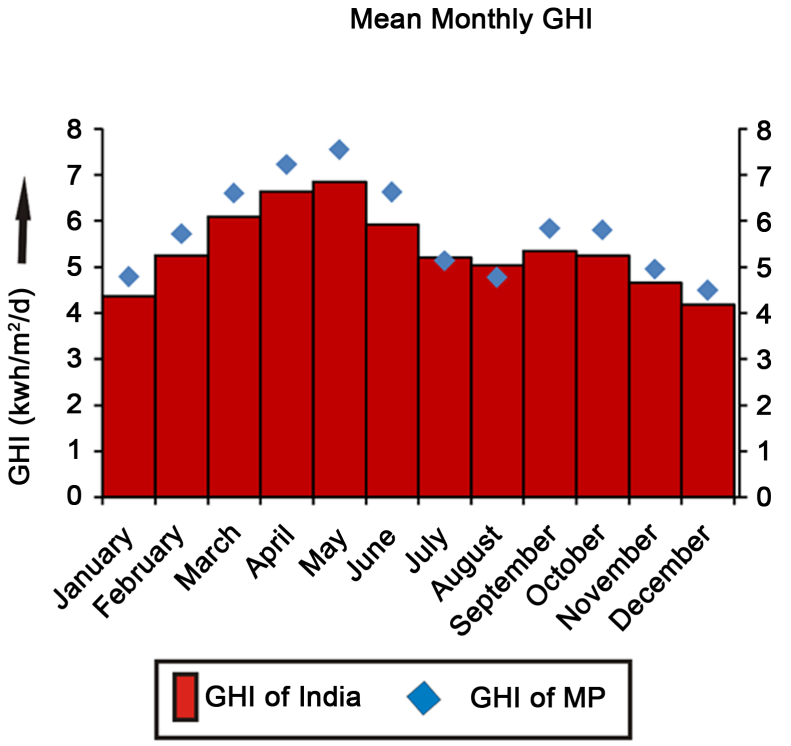

(b)

Figure 2. (a) MP has lowest installed rooftop capacity compared to other states; (b) MP have higher GHI average compared to Indian average. 


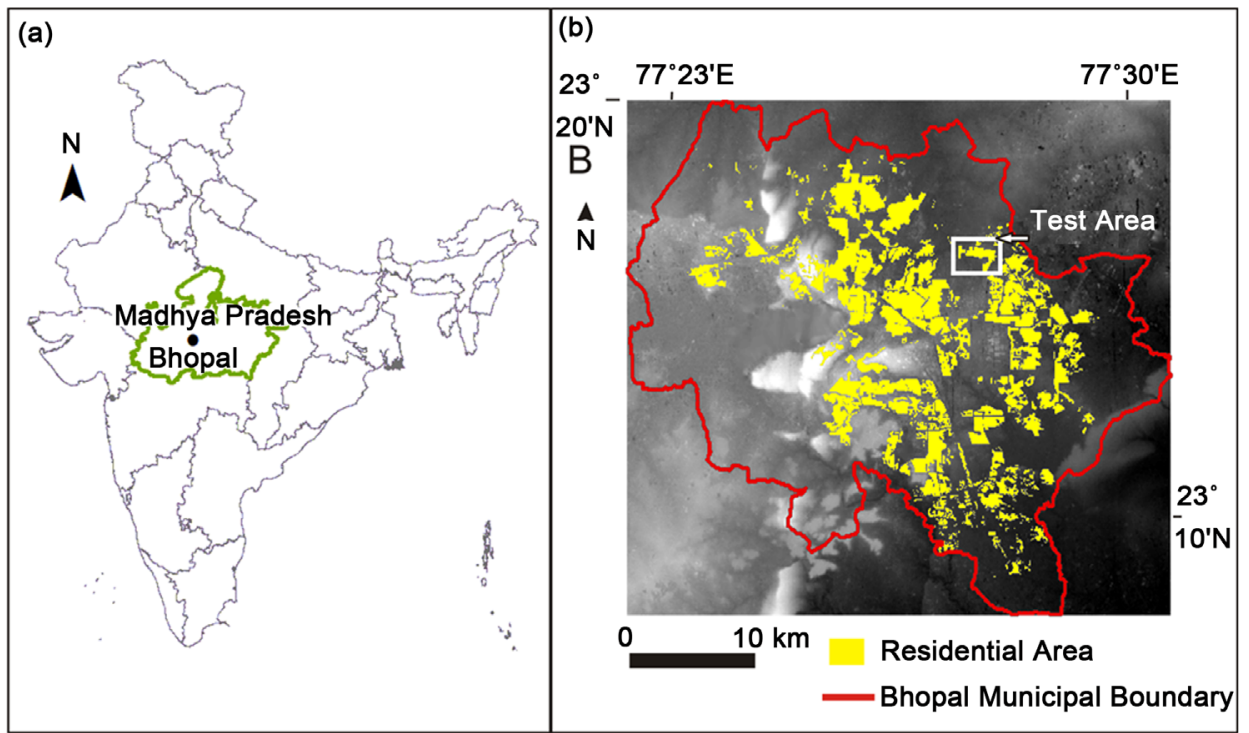

Figure 3. (a) Location of Bhopal within India; (b) Residential area within Bhopal Municipal Corporation (BMC).

Residential areas within the city boundary have been digitized using Bhopal Master Plan (2020) as reference and a small test area has been selected from amongst these areas (Figure 3(b)).

The selected test area is a gated residential neighbourhood developed by a private developer (Figure $4(\mathrm{a})$ ). The test area covers $0.89 \mathrm{sq} \cdot \mathrm{km}$ of area and has population of 7344. There are five types of plot areas but the residential is in the form of plotted row housing, height varying from two to three floors (Figure 4(b) and Figure 4(c)). Without tall trees and high rise buildings, roofs of residential buildings of the test site have the potential to get ample sunlight. Since it is a planned neighbourhood (Figure 4(a)), the test site is favourable for automated extraction of building rooftops.

In this study, World View 2 stereo pairs and multispectral imagery from Digital Globe Inc. has been used as base data for automated extraction. Stereo images are those when same area has been photographed with high resolution cameras installed at different angles. Specifications about the data are given in the Table 3.

\section{Methodology}

The method uses object-oriented classification available through eCognition Developer (v. 10). From total roof area, available rooftop area for PV installation is estimated by using MNRE standard, considering factors which influence the fraction of available roof area. Derived area is further used to estimate PV potential of entire residential area of Bhopal city.

Though the sample residential neighborhood covers only $1.83 \%$ of total residential area of Bhopal, considering only one sample neighborhood is the major limiting factor of this research. The focus of this paper is on the development of an approximation of total roof area. A separate simulation for determining suitable roof area from total roof 
(a)

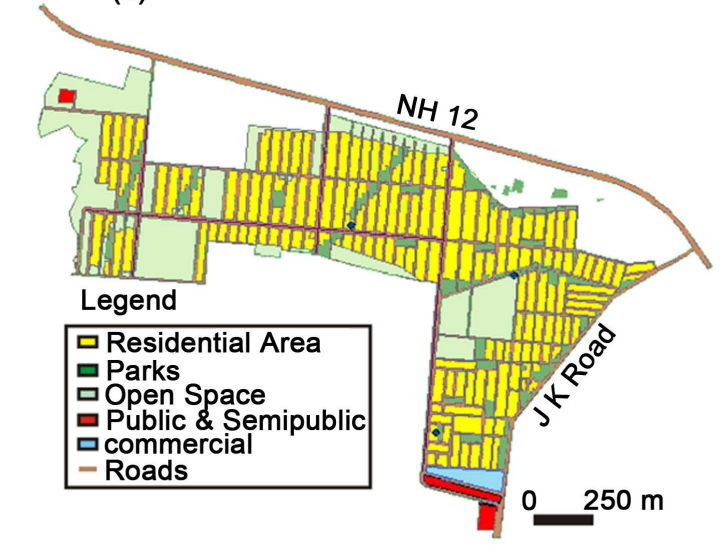

(b)
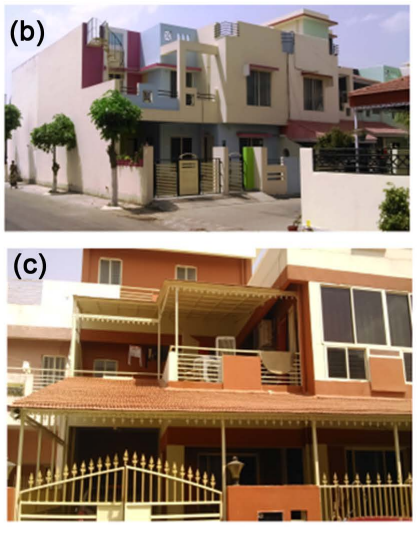

Figure 4. (a) Layout of the Test Area; (b) Two storey structure; (c) Three storey structure.

Table 3. WV2 data and test site description.

Coordinate system

Date of Acquisition

Lower left corner

Upper right corner

Spectral Bands

(Spatial Resolution and band width )

\section{UTM Zone 43N WGS84 ellipsoid}

$7^{\text {th }}$ February 2013

750067.500E $2575313.00 \mathrm{~N}$

$752061.50 \mathrm{E} 2576593.00 \mathrm{~N}$

$50 \mathrm{~cm}$ Panchromatic $(0.45-0.90 \mu \mathrm{m})$

$2 \mathrm{~m}$ Blue $(0.445-0.516 \mu \mathrm{m})$

$2 \mathrm{~m}$ Green $(0.506-0.595 \mu \mathrm{m})$

$2 \mathrm{~m}$ Red $(0.632-0.698 \mu \mathrm{m})$

$2 \mathrm{~m}$ Near-infrared (0.757 - $0.853 \mu \mathrm{m})$

area was outside the scope of this project, and hence, MNRE standard has been used. Future research can expand upon these aspects of this paper's results.

The proposed automated method for urban roof area extraction comprises of five steps:

1) Image pre-processing, 2) Production of reference map, 3) Automated extraction of total roof area using object-oriented classification, 4) Accuracy assessment of the automated method, 5) Estimating rooftop solar PV potential of the Test Area.

\subsection{Image Pre-Processing}

As rooftop and roads are composed with similar material they are seen the same way by satellite sensors. Elevation data plays a major role to segregate rooftops from roads. To get Elevation data, WV2 stereo pairs with $0.5 \mathrm{~m}$ spatial resolution are processed to produce $2 \mathrm{~m}$ Digital Surface Model or DSM (Figure 5(a)). A DSM represents elevation of every natural and/or artificial object like building, vegetation etc. as seen by sensor above the earth. To enhance the geo-positioning accuracy of DSM, 8 Ground Control Points (GCPs) acquired through high performance DGPS have been used. The DSM is 

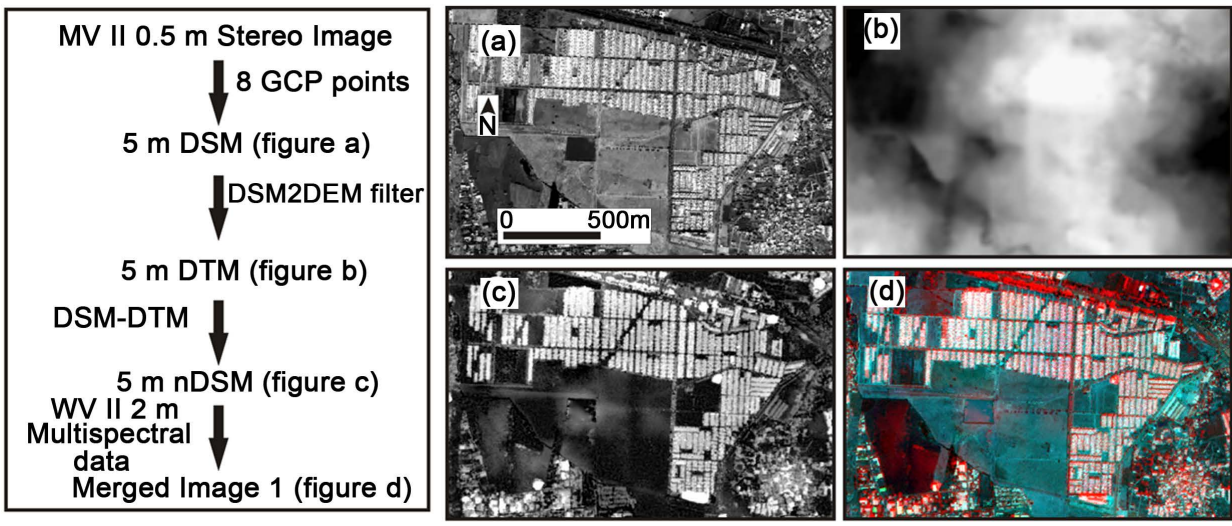

Figure 5. Flow chart describes building of thematic layer for identification of East Edge (see text for detail), with images showing intermediate outputs.

further filtered to produce DTM (Figure 5(b)) which shows the bare earth elevation. The DTM then is subtracted from DSM to produce nDSM (Figure 5(c)) which shows height of the objects standing over the earth's surface. This derived layer of nDSM is then merged with $2 \mathrm{~m}$ multispectral data from World View 2 and the new five-layer dataset "Merged Image 1" (Figure 5(d)) is used for all subsequent analysis in eCognition Developer. The entire process is accomplished by using Rolta Geomatica (2013).

\subsection{Production of Reference Map}

A reference map has been produced by performing on-screen digitization of building foot prints of the test area in eCognition Developer software itself. Multispectral image with $2 \mathrm{~m}$ spatial resolution from WV 2 is used for this purpose. As the dwelling units in the test area are row housing units, individual units are not visible in satellite image (Figure 6(a)). Each block consists of 8 to 36 houses/dwelling units and such blocks are separated by circulation paths. During digitization, each block is digitized as a single polygon and considered for total roof area extraction. These are being referred as building polygon in the following sections. Total 164 polygons were digitized and saved in vector format (Figure 6(b)). In order to extract statistics for the manually mapped building polygons, the vector layer was used to segment nDSM of the Test Area using Multiresolution (MS) segmentation in eCognition Developer (V.10). The MS segmentation starts with single image objects of one pixel and merges them iteratively, pair-wise and then in pairs of sets, into larger units until an upper threshold of homogeneity is locally exceeded. This homogeneity criterion is defined as a combination of spectral homogeneity and shape homogeneity. This calculation can be influenced by modifying the scale parameter: higher values result in larger image objects, while smaller values yield smaller image objects. The homogeneity criteria can be customized by assigning weight to shape and compactness criteria (eCognition Developer, 2014). In this case, larger weight was assigned to shape, to ensure that the nDSM is segmented into shapes that matched the predefined building polygons in the vector layer created by manual digitization (Figure 6(b)). The building polygons were extracted as individ- 


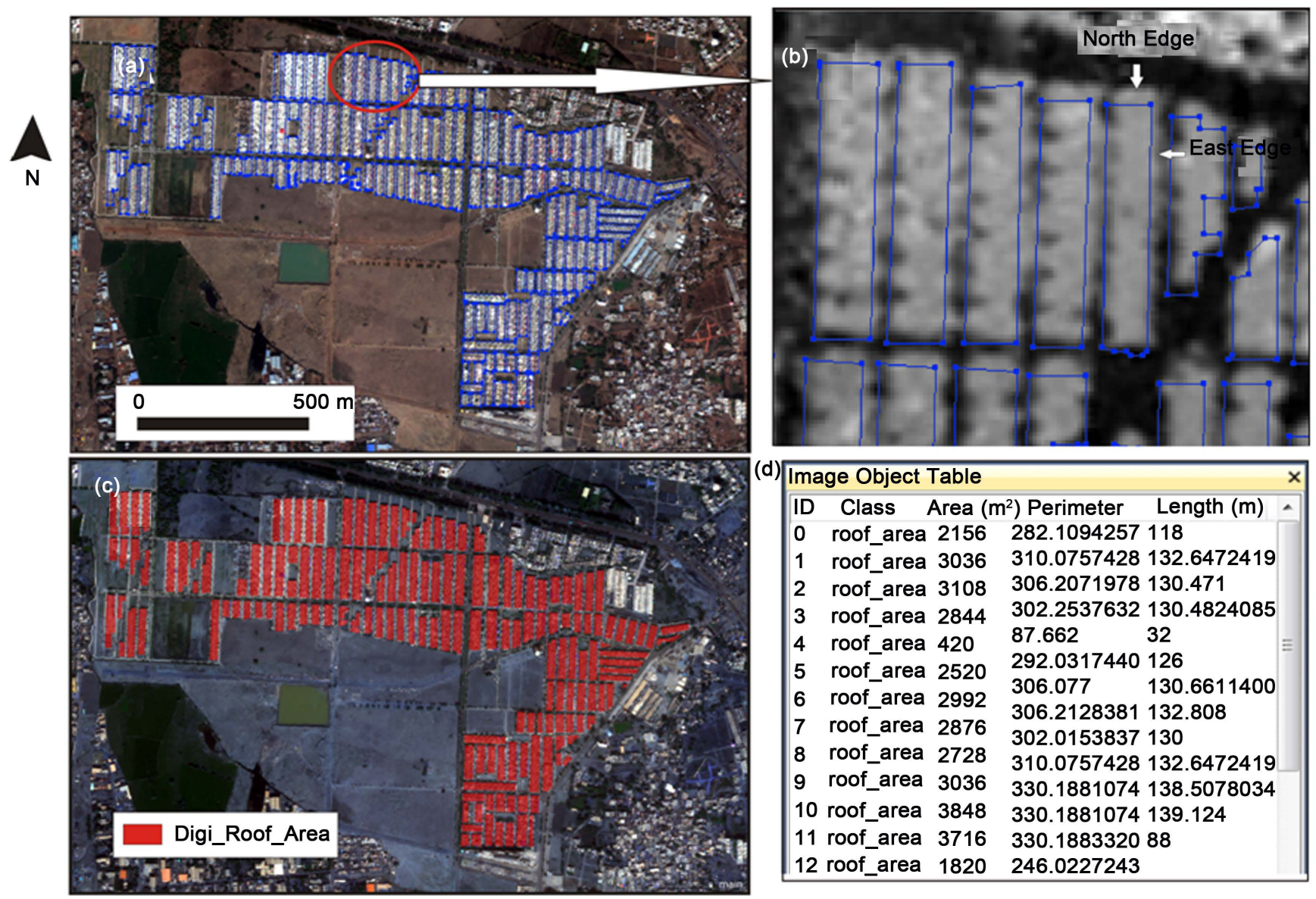

Figure 6. Preparation of reference data: (a) Building polygons are digitized on top of multispectral image; (b) Digitization of each block as single polygon; (c) The image objects for building polygons are classified under Digi_Roof_Area class; (d) Morphological parameters are obtained for each building polygon.

ual image objects and identified objects were classified as "Digi_Roof_Area" (Figure 6(c)). Morphometric data such as perimeter, area and length were collected for all building polygons and saved as a table of attributes for comparable analysis with the automated method (Figure 6(d)).

\subsection{Automated Extraction of Total Roof Area Using Object-Oriented Classification}

When manually digitized polygons are overlaid on the top of nDSM layer during reference data preparation, it was found that building polygons at nDSM contains more area around the edges (Figure 6(b)). To exclude this erroneous inclusion it was necessary to define boundaries for building polygons. They are termed as North and East Edge (Figure 6(b)). The method for automated extraction is performed in two steps. The first step involves automated extraction of edges as thematic layer. Then, the building polygons are extracted as individual objects using thematic layers as reference. Extracted building polygons represent the total roof area for each block since remote sensor see building in terms of rooftops from above. 


\subsubsection{Building Thematic Layers}

Thematic layers are the vector or raster files which provide underlying information for efficient classification (eCognition Developer, 2014). To extract east edges, relief shaded image was prepared from DSM using illumination angle perpendicular to building orientation. Sobel-edge detection algorithm was run on relief shaded image to accentuate the East Edge. It created an image with high pixel value where there is an edge (Figure 7(a)). Multiresolution (MS) segmentation was performed to extract edges as objects (Figure 7(b)). The objects then were further classified using membership function of layer values and orientation (Figure $7(\mathrm{c})$ ). The classified objects were then merged and converted to a vector file named "East Edge.shp" (Figure 7(d)).

North Edge is shadow areas of each block (Figure 8(a)). To mark shadow areas more prominently, edge detection filter is run on near infrared (NIR) layer of multispectral image which produces an image with higher value where there is a shadow (Figure 8(b)). This edge layer is segmented using MS segmentation and then classified using

\begin{tabular}{|c|c|}
\hline $\begin{array}{c}\text { Input 1 } \\
\text { Edge layer from } \\
\text { Relief Shaded image } \\
\text { (Figure a) }\end{array}$ & Classification \\
\hline $\begin{array}{c}\text { MS segmentation } \\
\text { (Figure b) }\end{array}$ & $\begin{array}{c}\text { Class: East Edge } \\
\text { Membership function: } \\
\text { Brightness, } \\
\text { Main Direction } \\
\text { (Figure c) }\end{array}$ \\
\hline $\begin{array}{c}\text { Segmented } \\
\text { Image }\end{array}$ & $\begin{array}{c}\text { East Edge. shp } \\
\text { (Figure d) }\end{array}$ \\
\hline
\end{tabular}
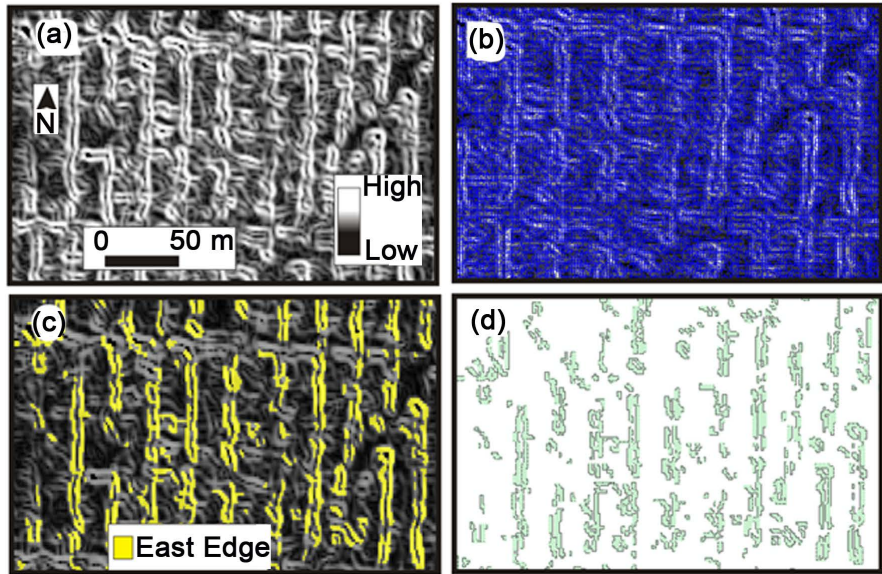

Figure 7. Flow chart describes building of thematic layer for identification of East Edge (see text for detail) with images showing intermediate outputs.
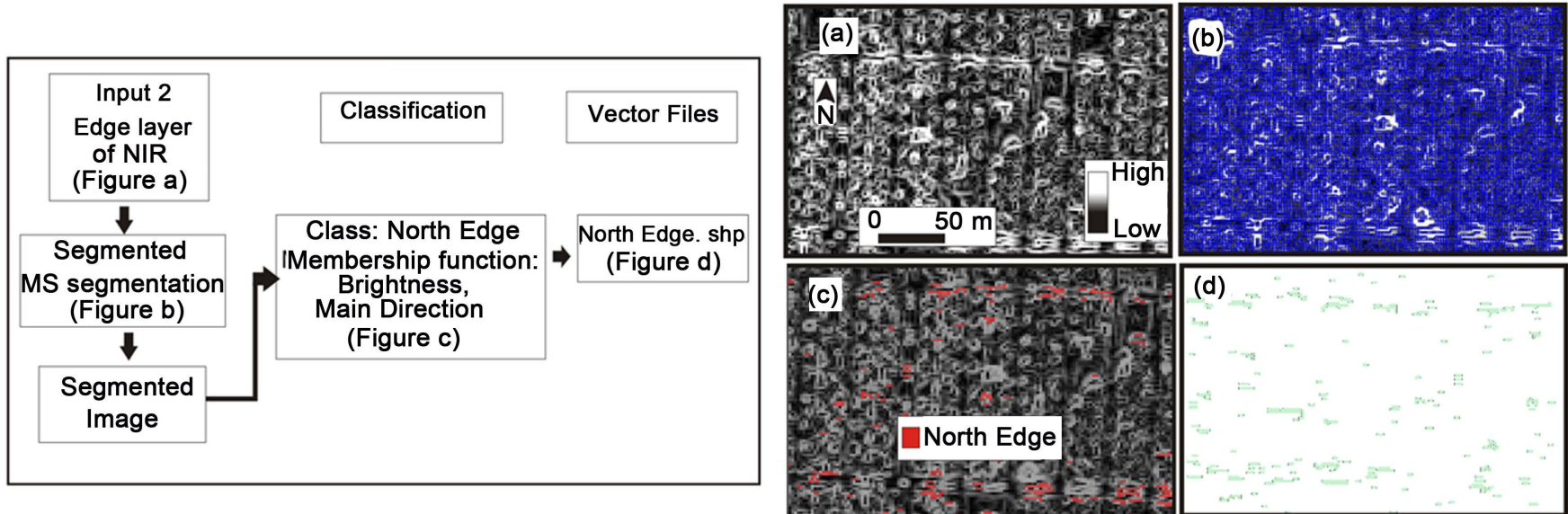

Figure 8. Flow chart describes building of thematic layer for identification of North Edge (see text for detail), with images showing intermediate outputs. 
membership function for layer value and orientation (Figure 8(c)). The classified objects were exported into "North Edge.shp" file (Figure 8(d)).

\subsubsection{Creating Individual Polygons for Building Blocks}

The second level of analysis started with merging the nDSM, Edge layers, Multispectral image to "Merged Image 2." MS segmentation is performed on this dataset, using East Edge.shp and North Edge.shp as thematic layers. To obtain adequate information from the vector layer, the scale parameter was set high (500), and shape and compactness were emphasized, by setting them at 0.9 and 0.5 , respectively (Figure 9(a)). After extracting East and North Edges for building polygons as objects they were classified thresholding edge value under the class East Edge and North Edge (Figure 9(b)). The unclassified objects were then further segmented using MS resolution and then classified using information regarding building height and contextual Relative Border to East and North Edges. The newly created class was named as "Final Rooftop" (Figure 9(c)). The Roof Area class contains individual polygon for each block. Lastly, the "Close Image Object" operation of the morphology algorithm was used to fill any gaps within building polygons (Figure 9(d)), simply by taking any as-yet unclassified pixels enclosed within the "Final Rooftop" class and adding them to that classified Rooftop area. The resultant image contained individual polygons under "Final Rooftop" class, which were further converted to vector file namely Final Rooftop.shp and were used in accuracy assessment.

\subsection{Accuracy Assessment of the Automated Method}

The process of accuracy assessment starts with visual comparison. For that purpose, manually mapped building polygons were overlaid on the automatically extracted polygons (Figure 10). According to the figure, automated method identified all building polygons mapped by manual method in its original location.

Close visual inspection reveals that some building polygons are extracted in multiple image objects rather than one continuous polygon (Figure 10). To find out whether
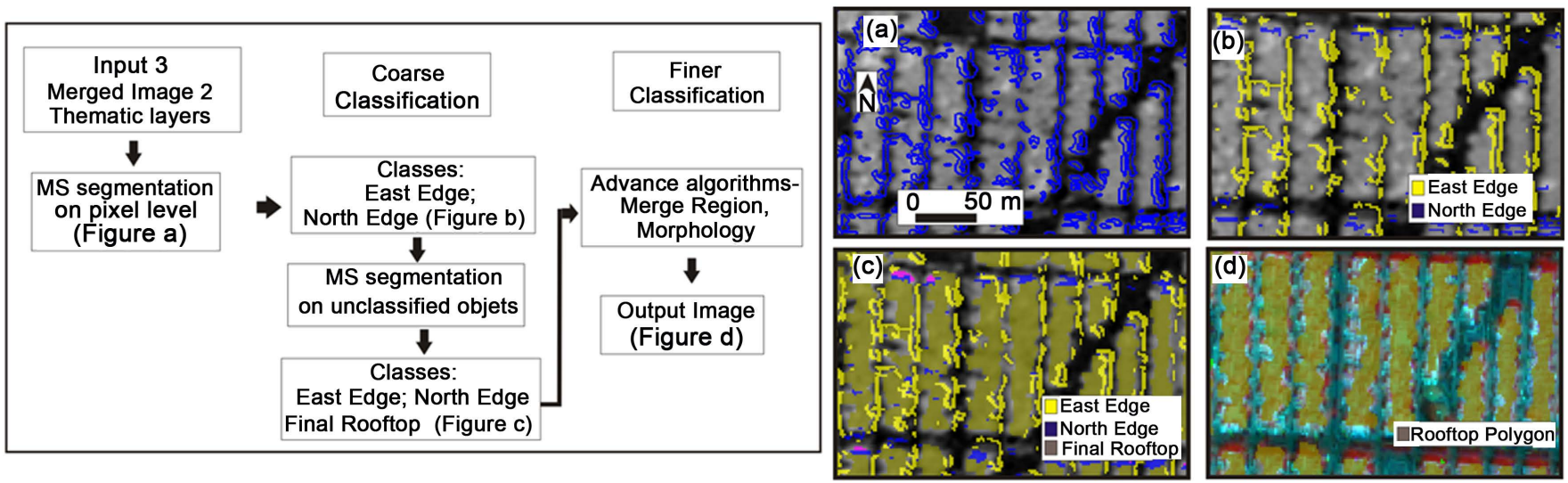

Figure 9. Flow chart and corresponding images are showing the automated extraction of building polygons. (a) A first round of segmentation toward extraction of edges; (b) North Edge and East Edge classes are shown in blue and yellow respectively; (c) Building polygons are extracted in relation to Edges; (d) Individual polygon for each block is extracted for entire test area. 


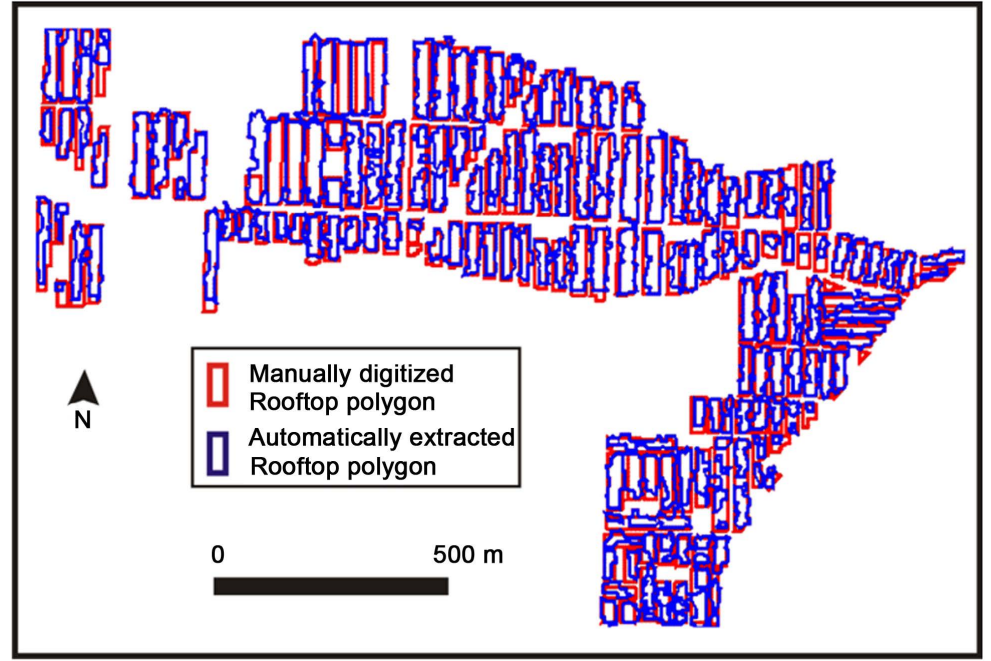

Figure 10. Visual comparison between automated and manually extracted drumlins.

that affected the accuracy level of the automated method, detailed statistical analysis was performed. For the purpose, 126 closely matched building polygons were identified. Data on morphological parameters were extracted for the two methods and recorded. Table 4 shows basic statistics of two sets of data.

According to the table, mean area and mean length for manually extracted building polygons are higher than the automated building polygons. On the other hand, mean value for perimeter of manually extracted building polygons is lower than the mean perimeter of automatically extracted building polygons (Table 4).

The significance of the differences between the two sets of results was evaluated with the nonparametric Mann-Whitney-Wilcoxon test (Table 5). This test was used in preference to the Student $t$ test because the latter assumes Gaussian distributions, and normality test presented in Table 4 shows that the parameters mostly failed normality with respect to Kolmogorov-Smirnov test. Results of the Mann-Whitney-Wilcoxon test (Table 5) show that parameters measured in the two different methods are statistically same except area.

There are, however, reasons to expect minor differences in the results of area calculations by the two methods. The manual method tends to favour idealized shapes that may not necessarily represent the absolute outer boundary of a building polygon. By comparison, the automated method follows the given rule set and thus drumlin boundaries are extended up to the threshold points of elevation and reflectance value, which tends to produce jagged, pixelated, and irregular sides (Figure 11). Definiens Developer calculates the area of an image object as the true area covered by one pixel multiplied by the number of pixels forming the image objects (eCognition Developer, 2014).

From the analyses, it may be concluded that the automated results using eCognition are not identical to results obtained by traditional "expert-judgment" methods, because eCognition identifies building polygons differently from subjective expert decisions taken during manual digitization. Moreover, expert recognition carries its own biases 


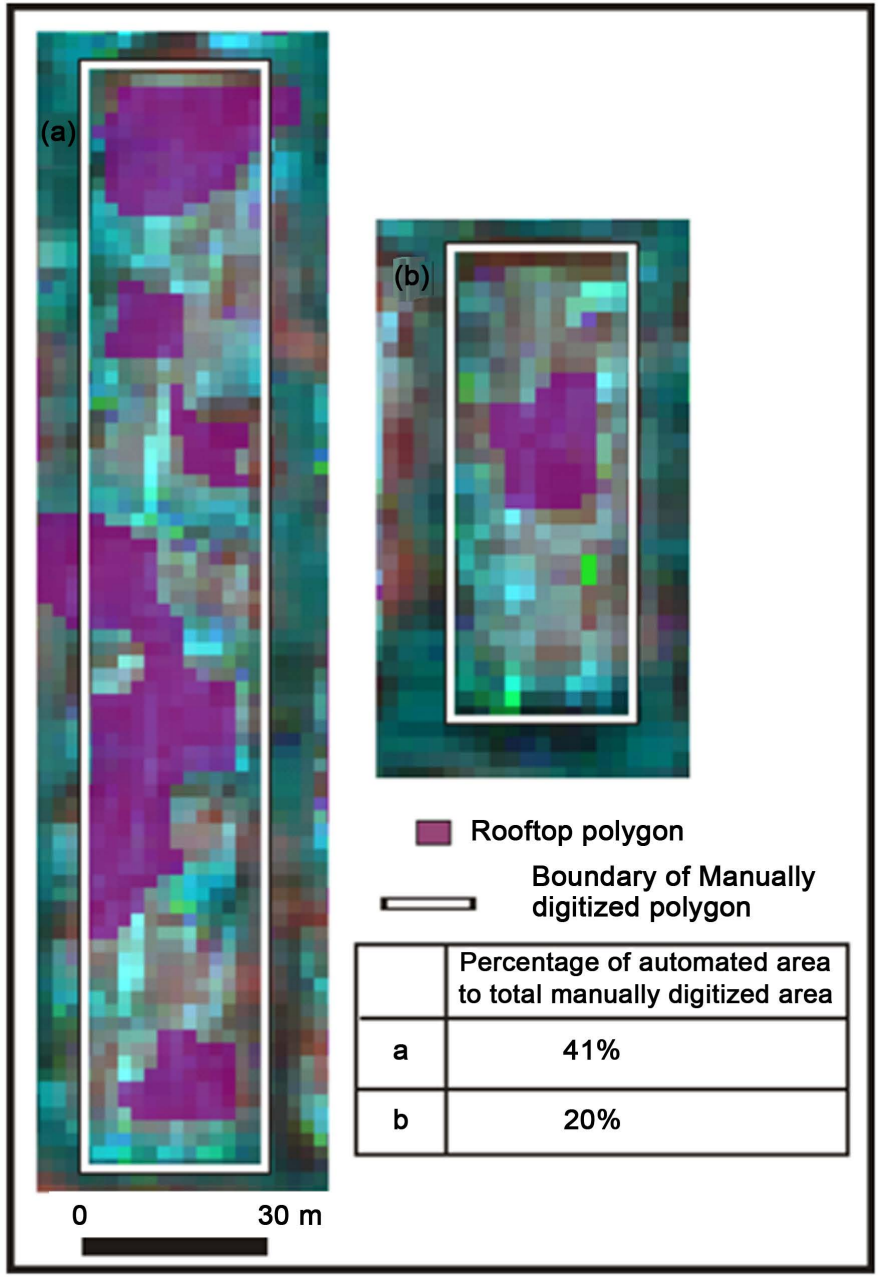

Figure 11. Example of building polygon extracted by automated method in irregular manner.

Table 4. Comparison of morphometry for 126 matched building polygons extracted by manual and automated methods.

\begin{tabular}{cccccc}
\hline \multicolumn{3}{c}{ Basic Statistics } & & Normality \\
\hline & Mean & Standard deviation & Max. & Min & Kolm.-Smirnov \\
\hline Length (m) & & & & \\
Manual & 97.49 & 34.32 & 178.72 & 34.00 & $\mathrm{nn}$ \\
Auto & 95.58 & 34.33 & 169.88 & 35.05 & $\mathrm{nn}$ \\
Perimeter (m) & & & & $\mathrm{nn}$ \\
Manual & 240.24 & 70.00 & 402.15 & 100.00 & $\mathrm{nn}$ \\
Auto & 250.55 & 82.61 & 437.23 & 96.70 & $\mathrm{nn}$ \\
Area (sqm) & & & & & $\mathrm{nn}$ \\
Manual & 2219.96 & 949.64 & 4676.00 & 544.00 & \\
Auto & 1976.47 & 1033.36 & 4820.00 & 312.00 & \\
\hline
\end{tabular}


Table 5. Mann-Whitney-Wilcoxon test of similarity in means.

\begin{tabular}{cccc}
\hline & Z score for U score & P value when $\alpha=0.05$ & MWW decision \\
\hline Length $(\mathrm{m})$ & -0.461 & 0.645 & same \\
Area (sqm) & -2.319 & 0.02 & different \\
Perimeter & -0.876 & 0.381 & same \\
\hline
\end{tabular}

and errors: buildings are understood to be mostly rectangular, data are likely to be subconsciously "corrected" to smooth and simple outlines during manual digitization. Interpreters tend not to separate small projections e.g., balconies, verandas, awnings from the building footprints, whereas, automated process tends to exclude these for different spectral reflectance.

eCognition offers the additional advantage of allowing the rules for recognition to be changed very easily, and then allowing the dataset to be re-collated almost instantaneously according to a new set of defined rules. Results, thus obtained from two different rule sets, can then be compared and selected as required. eCognition also allows data collection on a massive scale, literally thousands to tens of thousands of measurements with extreme ease. It may be further noted that even though the results of automated process are not identical to expert results, the statistics are at least reasonably consistent.

\subsection{Estimating Availability of Rooftop Area for Solar PV Installation in the Test Area}

Having obtained total roof area for a region, it is necessary to reduce this area to that which could be available for solar photovoltaic applications, in order to determine potential power output. There are many factors which influence the fraction of availability of the total roof area, e.g.: 1) shading, from other parts of the roof or from neighbouring buildings and trees; 2) use of roof space for other applications/elements, such as ventilation, heating/air conditioning, dormers or chimneys; 3) orientation of pitched roofs; and 4) the installation and racking of the PV panels themselves; 5) practice of using part of the roof for many household activities, including evening sit-outs, sleeping at night, clothes drying etc.

The primary focus of this paper is to develop a careful estimate of the total roof area in the region; a separate simulation or statistical analysis for obtaining reduction factors was outside the scope of the project and thus related literature (Scartezzini et al., 2002; Lehmann and Peter, 2003; Ghosh and Vale, 2006; Pillai and Banerjee, 2007; Izquierdo, 2008; Wiginton, 2010) are utilized to obtain approximate areas that would be available for solar PV installation.

The reduction process for this analysis is determined as follows. Firstly, building orientation must be accounted for. Buildings of the Test Area need not undergo any reduction for orientation since these are not built with pitched rooftops. Next, shading, other uses and installations must be accounted for. The lowest fraction obtained from literature review is 0.30 . This allows for the calculation of the fraction of un-shaded roof 
area which is unused for other purposes, including panel servicing and installation.

Thus, the roof area available for PV installation (APV) is the total roof area (ARoof) multiplied by the reported and chosen fraction as indicated below:

$$
\text { APV }=0.3 * \text { A Roof }
$$

Thus, for the Test area, APV $=(0.3) * 0.29 \mathrm{sqkm}=0.087 \mathrm{sqkm}$.

\subsection{Estimating Rooftop Solar PV Potential of the Test Area}

Power/energy output of Solar PVs depends on the type of photovoltaic panels used, since variations in efficiency exist across materials and manufacturers. There are two types of photovoltaic panels readily available in the Indian market: i) mono crystalline and ii) multi-crystalline silicon (often referred to as polycrystalline on the market). Among these two, multi-crystalline solar photovoltaic modules dominate the market due to higher efficiency. Table 6 summarizes energy output in Test Area using polycrystalline PV panels

Potential Energy output/day is calculated as:

$$
\mathrm{E}=\operatorname{Imd} * \mathrm{e} * \mathrm{APV}
$$

where "Imd" is the mean daily global insolation on a horizontal plane, calculated as an annual average, of $5.85 \mathrm{kWh} / \mathrm{m}^{2} /$ day (MNRE) and " $\mathrm{e}$ " is the module efficiency.

\subsection{Comparing Potential of Energy Output with Energy Demand of the Test Area}

To compare the potential of rooftop PV energy production with demand, daily energy demand of the Test Area has been estimated. Table 7 summarizes the daily energy de-

Table 6. Estimation of per capita energy output for test area.

\begin{tabular}{cccc}
\hline $\begin{array}{c}\text { Module } \\
\text { Type* }\end{array}$ & $\begin{array}{c}\text { Module } \\
\text { efficiency (\%) }\end{array}$ & $\begin{array}{c}\text { Potential Energy output } \\
\text { for Test Area (kwh/day) }\end{array}$ & $\begin{array}{c}\text { Potential Per-capita energy } \\
\text { output for Test Area (kwh/day) }\end{array}$ \\
\hline tp240 & 14.4 & 73288.80 & 9.98 \\
tp245 & 14.7 & 74815.65 & 10.19 \\
tp250 & 15 & 76342.50 & 10.40 \\
tp255 & 15.3 & 77869.35 & 10.60 \\
tp260 & 15.6 & 79396.20 & 10.81 \\
Average & 15 & 76342.50 & 10.40 \\
\hline
\end{tabular}

Table 7. Daily per capita energy consumption of the test area.

\begin{tabular}{cccccc}
\hline $\begin{array}{c}\text { Monthly } \\
\text { energy } \\
\begin{array}{c}\text { consumption } \\
(\mathrm{kwh} / \text { household })\end{array}\end{array}$ & $\begin{array}{c}\text { Daily energy } \\
\text { consumtion } \\
(\mathrm{kwh} / \text { household })\end{array}$ & $\begin{array}{c}\text { Daily energy } \\
\text { consumtion } \\
\text { for the Test } \\
\text { Area }(\mathrm{kwh})\end{array}$ & $\begin{array}{c}\text { Per capita } \\
\text { Energy } \\
\text { consumption } \\
(\mathrm{kwh} / \text { day })\end{array}$ & $\begin{array}{c}\text { Potential } \\
\text { energy output } \\
\text { for Test Area } \\
(\text { average }) \\
(\mathrm{kwh} / \text { day) })^{\#}\end{array}$ & $\begin{array}{c}\text { Potential } \\
\text { Per-capita } \\
\text { forgy output } \\
\text { (average }) \\
(\mathrm{kwh} / \text { day) }\end{array}$ \\
\hline 221.17 & 7.37 & 28743 & 3.91 & 76342.50 & 10.40 \\
\hline
\end{tabular}


mand at household level on per capita basis. In India, energy consumption data is recorded for electricity supply zone-wise feeder, and single feeder can supply energy to multiple administrative locations. Hence, it was near impossible to segregate the energy consumption data of the Test Area and as an alternate measure, a sample survey was conducted. Ten random sample households were selected from each of the five house types in the Test Area. For each type, household size and energy consumption data (monthly electricity bills for one calendar year) was recorded. Daily electrical energy consumption for total Test Area has been estimated from monthly average of electrical energy consumption for each household (Table 7).

As may be noted from Table 6 [also indicated in Table 7 for comparison], potential output from the large-scale deployment of rooftop PV is large [with efficient polycrystalline-silicon panels] and on an average, $10.40 \mathrm{kwh} /$ capita energy can be produced daily. Table 7 indicates that per capita daily energy consumption is $3.91 \mathrm{kwh}$. It implies that rooftop solar PV can provide 265\% of daily energy requirement for Test Area and after meeting its own demand, has the potential to contribute $165 \%$ of its daily demand to the electricity supply grid if net metering system is adopted.

\section{Discussion on Issues and Policy Implications}

The results indicate that rooftop solar PV in residential area alone has considerable potential to provide power into the electricity supply grid for consumption in all areas/ sectors including residential, commercial and industrial sectors thereby meeting the growing energy demand in the cities without contributing to GHG emissions. However, installation of rooftop solar PV in residential areas has not gained momentum owing to many reasons:

- The schemes/incentives/means for promoting rooftop solar PV programs adopted by government [as indicated in Table 2] target larger capacity installations not suitable for small sized units which can be installed on small residential unit/attached type residential block [row housing/terraced (as in test area) or apartment block] roof tops.

- Attached residential units in the form of blocks pose a further issue of multiple ownerships.

- Current incentives and schemes are suitable for agencies and organisations [private and government] and not individual residential residents or housing associations/housing cooperatives in terms of financial mechanisms and solar PV operation related aspects.

- Residents in Indian cities may be divided in a few classes: a) Deprived, b) Aspirers, c) Middle Income [Seekers], d) Middle Income [Strivers], e) Globals [Rich/High Income] (McKinsey \& Company, 2007). The classes are in ascending order of economic capability and it was forecast by McKinsey \& Company that in 2015, the first three groups would comprise $97 \%$ of Indian population. While considering the cities only, this percentage will reduce, however it still remains very high. For these classes, affording the capital investment required for acquiring houses remain very 
difficult and making additional capital investment required for rooftop solar PV installation is not going to be popular.

- In view of the aforementioned issues, possibility of renting part of the roof area to solar energy producing entities comes into focus together with exemption from conversion of residential tax to commercial tax.

A draft policy prepared by state government of NCT Delhi (Delhi Solar Energy Policy, 2015) attempts to address some of these issues by having separate promotional policies for three different categories of rooftop solar PV installation locations, namely: a] Government/public institutions, b] Commercial and industrial establishments, c] Residential consumers. It further proposes to promote "net metering", "group net metering" [adjustment of surplus energy at other location] and "virtual net metering" [in case of multiple ownerships].

It further proposes that the SNA [State Nodal Agency] shall:

- Assist project developers in identifying the technically feasible sites/roofs,

- Encourage deployment of solar plants on sites under the jurisdiction of private institutions/buildings that are not mandated as per the Policy,

- Play a key role in the aggregation of potential rooftop projects,

- Provide guidelines for technical and commercial assessment of competitive bids.

Though the draft policy attempts to address some of the issues raised and stated earlier, but the approach is likely to succeed at locations of: a) Government/public institutions, b) Commercial and industrial establishments only. Residential consumers will lose out unless there is a dedicated agency/cell working in tandem with or under the direction of SNA for monitoring the activities such as: identifying potential sites, bringing all parties together [resident associations/housing cooperatives, commercial party acting as aggregator, energy producer/renewable energy service companies and energy distribution companies], preparing project reports, obtaining approvals, undertaking bidding process and monitoring execution of work.

Hence, for success of the ongoing JNNSM, it is imperative that, in line of the discussion as above and as already proposed to some extent in the draft policy of NCT Delhi, all the state governments bring about changes in their solar energy related policies.

\section{Conclusion}

This paper proposed an automated object-oriented approach to extract total available area of residential rooftops using Stereo pair and Multispectral images in eCognition Developer (V.10) and applying procedure of multi-resolution segmentation followed by rule-based classification. A small residential neighbourhood in Bhopal city was selected as Test Site to test the proposed method.

An accuracy assessment of the extraction was carried out with respect to manually digitized total roof area. Mean area and mean length for manually extracted building polygons were found to be higher than the automated building polygons. On the other hand, mean value for perimeter of manually extracted building polygons is found to be lower. Further, a comparison of morphometry for 126 matched building polygons ex- 
tracted by manual and automated methods was carried out. Mann-Whitney-Wilcoxon test shows that parameters measured in the two different methods are statistically same except area parameter.

From the analyses, it was concluded that the automated results are close but not identical to results obtained by traditional method of manual digitization. However, it was assumed to be nearer to true measurements as manual digitization has its own influencing biases and errors.

The extracted roof area was further reduced to available roof area for solar PV installation using a fraction based on literature survey. Potential of this available roof area for solar energy production was estimated using specifications and company stated output capacities of multi-crystalline solar photovoltaic modules. It is found that the test area has the potential to meet $265 \%$ of its daily local energy demand through rooftop solar PV panels.

However, use of solar photovoltaic technologies is complicated because, temporally and seasonally solar irradiation vary, also if not electricity distribution grid connected, it requires energy storage facilities as production and consumption timings do not match.

Due to many reasons, residential rooftop solar PV has not yet become popular in India and particularly in state of Madhya Pradesh where the research has been carried out. As pointed out in discussions, for success of JNNSM, a dedicated agency/cell is required to work in tandem with or under the direction of State Nodal Agency for monitoring the rooftop solar PV installation and operation related activities. These activities include, inter alia, activities of identifying the technically feasible sites/roofs, formulation of solar rooftop projects, aggregation of potential rooftop projects, etc.

The proposed and researched method of rooftop extraction in residential areas as presented in this paper would help to undertake the aforesaid activities and greatly reduce the time required.

The research may be further developed in two ways. Firstly, results of the automated extraction may be compared with actual construction drawings in test cases where available and if required the output data may be suitably calibrated. Secondly, reduction of the "extracted total rooftop" to "available rooftop for solar PV installation" requires further research to develop different suitable fractions for different types of residential areas based on their inherent characteristics.

\section{Acknowledgements}

The authors would like to thank and acknowledge the Department of Science and Technology, Government of India for funding this research vide Project No. SR/FTP/ ES-24/2012. The authors would also like to thank School of Planning and Architecture Bhopal for procuring WV2 satellite imageries.

\section{References}

Aldred, D. W. (2011). A Method for Obtaining and Applying Classification Parameters in Ob- 
ject-Based Urban Rooftop Extraction from VHR Multispectral Images. International Journal of Remote Sensing, 32, 2811-2823. http://dx.doi.org/10.1080/01431161003745590

Delhi Solar Energy Policy (2015). Draft Version for Public Comment. New Delhi: Government of NCT of Delhi.

eCognition Developer (2014). Userguide Version 9 (270 p). Munich: Trimble Germany GmbH.

Ghosh, S., \& Vale, R. (2006). Domestic Energy Sustainability of Different Urban Residential Patterns: A New Zealand Approach. International Journal of Sustainable Development, 9, 16-37. http://dx.doi.org/10.1504/IJSD.2006.010936

Giada, S., De Groeve, T., Ehrlich, D., \& Soille, P. (2003). Information Extraction from Very High-Resolution Satellite Imagery over Lukole Refugee Camp, Tanzania. International Journal of Remote Sensing, 24, 4251-4266. http://dx.doi.org/10.1080/0143116021000035021

Herold, M. S. (2002). Object-Oriented Mapping and Analysis of Urban Land Use/Cover Using IKONOS Data. In T. Benes (Ed.), Proceedings of the 22nd EARSEL Symposium (pp. 531-538). Rotterdam: Mill Press.

Hofierka, J., \& Kaňuk, J. (2009). Assessment of Photovoltaic Potential in Urban Areas Using Open-Source Solar Radiation Tools. Renewable Energy, 34, 2206-2214.

http://dx.doi.org/10.1016/j.renene.2009.02.021

Izquierdo, S., Rodrigues, M., \& Fueyo, N. (2008). A Method for Estimating the Geographical Distribution of Available Roof Surface Area for Large-Scale Photovoltaic Energy-Potential Evaluations. Solar Energy, 82, 929-939. http://dx.doi.org/10.1016/j.solener.2008.03.007

Lehmann, H., \& Peter, S. (2003). Assessment of Roof \& Façade Potentials for Solar Use in Europe. Aachen: Institute for Sustainable Solutions and Innovations (ISUSI). http://sustainable-soli.com/downloads/roofs.pdf

Marangoz, A. O. (2004). Object-Oriented Image Analysis and Semantic Network for Extracting the Roads and Building from IKONOS Pan-Sharpened Images. In M. Altan (Ed.), Proceedings of the International Society for Photogrammetry and Remote (pp. 393-396). Istanbul: ISPRS. www.isprs.org

MNRE. India Solar Resource MAPs. http://mnre.gov.in/sec/solar-assmnt.htm

Neuhoff, K. (2005). Large-Scale Deployment of Renewables for Electricity Generation. Oxford Review of Economic Policy, 21, 88-110. http://dx.doi.org/10.1093/oxrep/gri005

Pearce, J. M. (2002). Photovoltaics: A Path to Sustainable Futures. Futures, 34, 663-674. http://dx.doi.org/10.1016/S0016-3287(02)00008-3

Saha, K., Wells, N. A., \& Munro-Stasiuk, M. (2011). An Object-Oriented Approach to Automated Landform Mapping: A Case Study. Computers \& Geosciences, 37, 1324-1336. http://dx.doi.org/10.1016/j.cageo.2011.04.001

Scartezzini, J.-L., Montavon, M., \& Compagnon, R. (2002). Computer Evaluation of the Solar Energy Potential in an Urban Environment.

Shackelford, A., \& Davis, C. H. (2003). A Combined Fuzzy Pixel-Based and Object-Based Approach for Classification of High-Resolution Multispectral Data over Urban Areas. IEEE Transactions on Geoscience and Remote Sensing, 41, 2354-2363. http://dx.doi.org/10.1109/TGRS.2003.815972

Vardimon, R. (2011). Assessment of the Potential for Distributed Photovoltaic Electricity Production in Israel. Renewable Energy, 36, 591-594.

http://dx.doi.org/10.1016/j.renene.2010.07.030

Wiginton, L., Nguyen, H. T., \& Pearce, J. M. (2010). Quantifying Rooftop Solar Photovoltaic Potential for Regional Renewable. Computers, Environment and Urban Systems, 34, 345-357. http://dx.doi.org/10.1016/j.compenvurbsys.2010.01.001 
Submit or recommend next manuscript to SCIRP and we will provide best service for you:

Accepting pre-submission inquiries through Email, Facebook, LinkedIn, Twitter, etc. A wide selection of journals (inclusive of 9 subjects, more than 200 journals)

Providing 24-hour high-quality service

User-friendly online submission system

Fair and swift peer-review system

Efficient typesetting and proofreading procedure

Display of the result of downloads and visits, as well as the number of cited articles

Maximum dissemination of your research work

Submit your manuscript at: http://papersubmission.scirp.org/

Or contact cus@scirp.org 